\title{
Pengaruh Salinitas Air Laut Terhadap Laju Korosi Pada Plat Lambung Kapal Bobot 1500 DWT
}

\author{
Sutrisno Lilik Budiyanto ${ }^{\mathrm{a}^{*}}$ \\ ${ }^{a}$ Universitas Maritim Amni Semarang \\ a*Email: Budiyantolilik@ gmail.com
}

\begin{abstract}
ABSTRAK
Kapal adalah alat transportasi di atas laut, di mana kapal memegang peranan vital dalam aspek sosial ekonomi melalui fungsi distribusi antara daerah satu dengan daerah yang lain. Bagian kapal yang sering mengalami kerusakan salah satunya adalah lambung kapal. Penyebab kerusakan lambung kapal adalah korosi. Aspek tinggi rendahnya tingkat korosi pada lambung kapal adalah kandungan salinitas pada air laut. Penelitian ini bertujuan untuk mengetahui pengaruh salinitas pada air laut terhadap laju korosi pada plat lambung kapal dengan media air laut yang diambil pada perairan Pelabuhan Tanjung Emas Semarang. Penelitian ini menggunakan metode uji eksperimen kehilangan berat (weight loss) merujuk standar ASTM G31-72. Dengan spesimen yang dibuat kupon untuk dihitung berat sebelum perendaman dan perhitungan berat setelah perendaman. Perendaman dilakukan selama 7 hari di dalam instalasi korosi yang dipersiapkan. Hasil dari penelitian ini menunjukan bahwa air laut yang memiliki kandungan salinitas lebih tinggi dibanding air payau dan air tawar memiliki laju korosi yang lebih tinggi dibanding spesimen kupon yang lain.
\end{abstract}

Kata Kunci: lambung kapal, korosi, salinitas

\section{ABSTRACT}

Ships are a means of transportation over the sea, where ships play a vital role in the socio-economic aspect through their distribution function between regions. One part of the ship that is often damaged is the hull of the ship. The cause of hull damage is corrosion. The aspect of high and low level of corrosion on the hull is the salinity content in seawater. This study aims to determine the effect of salinity in seawater on the rate of corrosion on the hull plate with seawater media taken from the waters of the Port of Tanjung Emas Semarang. This study used an experimental test method of weight loss (weight loss) referring to the ASTM G31-72 standard. With specimens made coupons to calculate the weight before immersion and weight calculation after soaking. Soaking is carried out for 7 days in the prepared corrosion installation. The results of this study indicate that seawater which has a higher salinity content than brackish water and fresh water has a higher corrosion rate than other coupon specimens.

Keywords: hull, corrosion, salinity

\section{PENDAHULUAN}

Lambung kapal atau dalam bahasa Inggris disebut hull adalah badan dari perahu atau kapal. Lambung kapal menyediakan daya apung (Bouyancy) yang mencegah kapal dari tenggelam yang dirancang agar sekecil mungkin menimbulkan gesekan dengan air, khususnya untuk kapal dengan kecepatan tinggi (Okumoto et al., 2009; 
Pérez \& Clemente, 2011). Dalam operasinya kapal berlayar di atas air laut di mana lingkungan tersebut merupakan lingkungan korosif yang tinggi (Li et al., 2015; Refait et al., 2018). Statistik pada penelitian sebelumnya menunjukan kurang lebih $90 \%$ kerusakan yang mengakibatkan kerusakan kapal terutama di bagian lambung disebabkan oleh korosi (Gong et al., 2020; Zayed et al., 2018). Di Indonesia jumlah kecelakaan kapal periode tahun 20102016 akibat tenggelam karena kebocoran kapal mencapai $37 \%$ dari semua jenis kecelakaan (Komite Nasional Keselamatan Transportasi RI, 2016).

Korosi adalah degradasi pada suatu logam oleh reaksi kimia dengan lingkungannya. Korosi merupakan sumber dari kerusakan terbesar yang terjadi pada kapal karena mengakibatkan fatique life dan berkurangnya kecepatan kapal (Bialystocki \& Konovessis, 2016; $\mathrm{Hu}$ et al., 2021). Kandungan material yang terdapat dari media air laut memiliki faktor dalam korosi logam secara cepat. Ada dua aspek yang memengaruhi proses korosi yaitu dari material itu sendiri (komposisi dan perlakukan yang dilakukan) dan dari faktor lingkungan seperti salinitas (kadar garam), efek $\mathrm{Ph}$ (derajat keasaman), temperatur dan kecepatan (Abbas \& Shafiee, 2020; Sasono, 2010). Semakin tinggi salinitas maka semakin tinggi laju korosi yang terjadi. Jika dalam kondisi sebenarnya, maka perairan yang memiliki kadar salinitas lebih tinggi bisa menyebabkan korosi yang lebih tinggi (Kim et al., 2020).

Pada penelitian ini dilakukan pengukuran kandungan salinitas pada air laut tanpa diganti, air laut selalu diganti dan air payau di area Pelabuhan Tanjung Emas Semarang.

Pada penelitian ini juga dilakukan perhitungan laju korosi pada plat lambung kapal dengan medium perendaman air laut pada area pelabuhan Tanjung Emas Semarang.

https://doi.org/10.46484/db.v2i1.256

\section{METODE}

\section{Material}

Spesimen yang digunakan pada penelitian ini adalah potongan plat baja yang dipakai pada lambung kapal. Material dilakukan uji komposisi sebelum dilakukan uji korosi. Uji komposisi menggunakan peralatan XRF (X Ray Fluerence). Ukuran spesimen uji korosi memiliki tebal $8 \mathrm{~mm}$, panjang 75 $\mathrm{mm}$ lebar $8 \mathrm{~mm}$ dan memiliki lubang pada spesimen dengan ukuran $(4,5 \mathrm{~mm})$ untuk fasilitas peletakan spesimen pada peralatan uji. Jumlah spesimen ada 3 buah yang diletakkan pada instalasi kupon. Spesimen tersebut dipakai untuk mengukur laju korosi. ASTM D 268805. Ukuran kupon dapat dilihat pada gambar 1 di bawah ini:

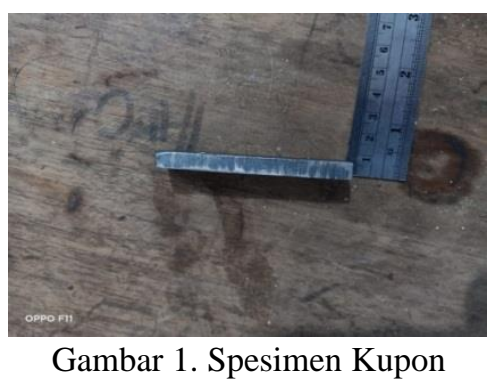

\section{Pengambilan Media Air Laut}

Dalam perhitungan laju korosi pada kupon dilakukan variabel media perendam yaitu air laut, air payau, dan air laut selalu diganti. Adapun air laut diambil dari Pelabuhan Tanjung Emas Semarang. Gambar di bawah ini adalah gambar proses pengambilan media air laut dapat dilihat di bawah ini:

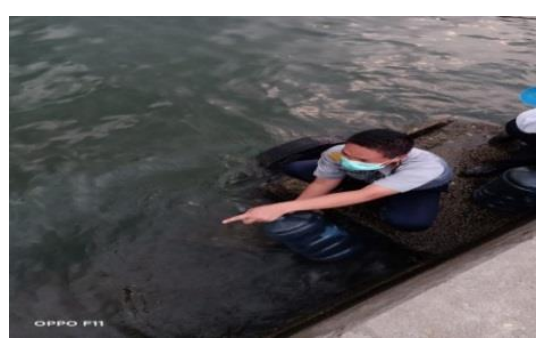

Gambar 2. Proses Pengambilan Air Perendaman

\section{Pengujian Salinitas Air Laut}

Pengujian salinitas air laut menggunakan alat ukur salinometer dan 
dilakukan setiap hari selama 7 hari selama proses perendaman spesimen kupon pada instalasi kupon korosi. Gambar proses pengambilan data kandungan salinitas dapat dilihat di bawah ini:

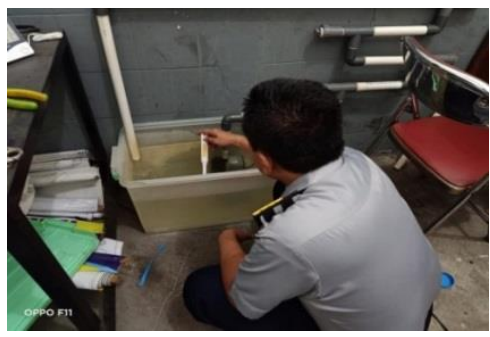

Gambar 3. Proses Pengambilan Salinitas Air Laut

4. Pengujian Komposisi Plat Baja

Pengujian komposisi kimia pada spesimen kupon dilakukan di laboratorium terpadu Universitas Diponegoro menggunakan XRF ( $X$ ray Fluerence). Pengujian ini dilakukan untuk mengetahui unsur kimia yang terkandung di dalam plat baja yang sebelumnya belum diketahui kandungan kimianya.

5. Pengujian Korosi

Sebelum dipasang di dalam instalasi kupon, spesimen kupon dilakukan penimbangan awal kemudian spesimen dipasang pada instalasi kupon yang sudah dirancang dengan standar ASTM D 2688-05, spesimen kupon dipasang pada tempat yang sudah disediakan dalam instalasi korosi kupon dengan variabel air perendaman yang berbeda (ASTM International, 2015). Alat uji pengujian korosi dapat dilihat di bawah ini:

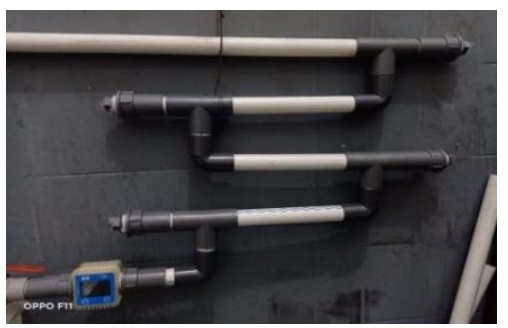

Gambar 4. Instalasi Korosi Kupon
6. Penimbangan Akhir

Specimen kupon yang telah dipasang pada instalasi korosi kupon dengan media perendaman air laut dan air payau selama 7 hari, spesimen kupon dibersihkan dari kotoran dan kemudian dilakukan penimbangan dengan timbangan mikro gram balance agar diketahui perbedaan berat sebelum perendaman dan setelah perendaman. Gambar di bawah ini adalah gambar penimbangan spesimen.

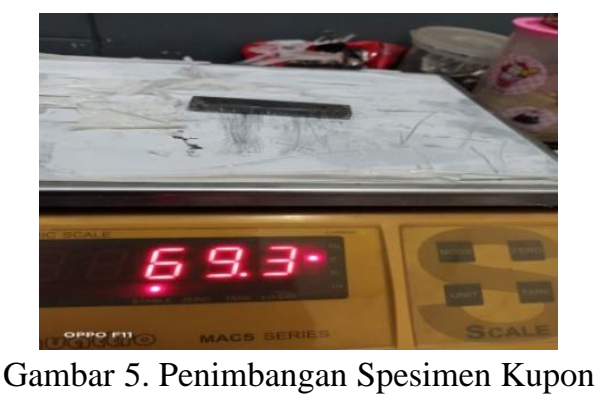

\section{Perhitungan Laju Korosi}

Laju korosi dapat ditentukan dengan menggunakan persamaan sebagai berikut :

$$
\mathrm{MPY}=\frac{534 \mathrm{~W}}{\mathrm{D} \cdot \mathrm{A} \cdot \mathrm{T}}
$$

Dimana : $\mathrm{W}=$ massa yang hilang akibat terkorosi, milligram (mg); $\mathrm{D}=$ rapat massa, gram per sentimeter kubik (gr/cm3); 7, 8 g/cm3 [3, hal. 374], $\mathrm{A}=$ luas permukaan, square inches (in2); $\mathrm{T}=$ lama pengujian (jam). Untuk mengetahui baik tidaknya cat sebagai pelindung untuk menghambat laju korosi dapat dibandingkan dengan kriteria yang disajikan dalam literature.

\section{HASIL DAN PEMBAHASAN}

1. Komposisi Plat Lambung Kapal

Hasil dari pengujian komposisi spesimen plat lambung kapal dengan XRF diketahui memiliki kandungan seperti disebutkan pada tabel di bawah ini: 
Tabel 1. Komposisi Spesimen Plat

\section{Nama Unsur Material Spesimen}

\begin{tabular}{ll}
\hline Karbon (C) & $0,265 \%$ \\
Phosporus (P) & $0,376 \%$ \\
Sulfur (S) & $0,054 \%$ \\
Silicon (Si) & $0,045 \%$ \\
\hline
\end{tabular}

Dari hasil uji komposisi plat lambung kapal dengan dibandingkan kandungan komposisi standar ASTM diketahui bahwa spesimen plat tersebut merupakan jenis baja A36.

\section{Salinitas Air}

Pengukuran kandungan garam (salinitas) pada variabel air perendaman selama 7 hari di dalam sirkulasi instalasi kupon dengan hasil sebagai berikut:

Tabel 2. Hasil Pengukuran Salinitas

\begin{tabular}{|c|c|c|c|}
\hline Hari & $\begin{array}{r}\text { AL tidak } \\
\text { diganti \% }\end{array}$ & $\begin{array}{c}\mathbf{A L} \\
\text { diganti } \\
\%\end{array}$ & Payau \% \\
\hline 1 & 0,3 & 1,3 & 0,3 \\
\hline 2 & 0,8 & 1,3 & 0,8 \\
\hline 3 & 0,8 & 1,0 & 0,8 \\
\hline 4 & 1,2 & 1,0 & 0,8 \\
\hline 5 & 1,7 & 1,0 & 0,8 \\
\hline 6 & 1,8 & 1,0 & 0,8 \\
\hline 7 & 2,0 & 0,8 & 0,8 \\
\hline $\begin{array}{l}\text { Rata rata } \\
\%\end{array}$ & 1,2 & 1,0 & 0,7 \\
\hline
\end{tabular}

Dari hasil pengukuran salinitas diketahui bahwa air laut yang tidak diganti memiliki salinitas paling tinggi dengan nilai rata rata 1,2 \%.

\section{Laju Korosi}

Pengujian korosi dalam penelitian ini dilakukan selama 7 hari. Variabel yang dilakukan dengan menggunakan air perendaman air laut tidak diganti, air laut diganti dan air payau yang diambil dari perairan Pelabuhan Tanjung Emas Semarang.

Hasil dari pengujian korosi yang dilakukan dalam penelitian ini dinyatakan dalam MPY adapun hasilnya dapat dilihat dalam gambar grafik di bawah ini:

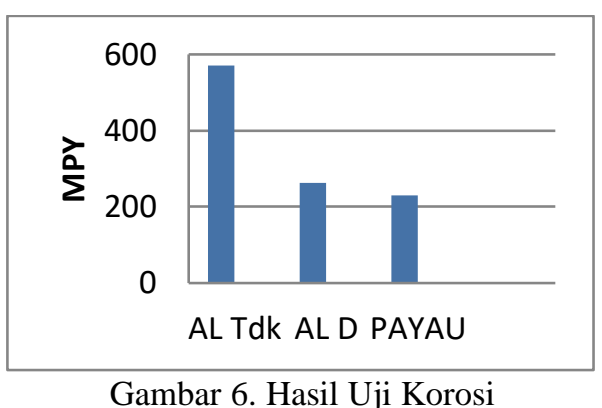

Dari gambar 6 hasil pengujian korosi memperlihatkan bahwa variabel air rendaman tanpa diganti memiliki nilai laju korosi 571,91 MPY.

4. Hubungan Salinitas dan Laju

Korosi

Berdasarkan hasil perhitungan salinitas dan perhitungan laju korosi yang telah dilakukan didapat data sebagai berikut:

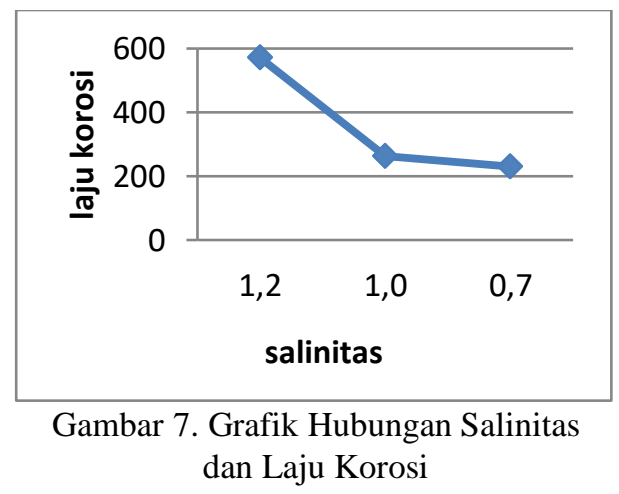

Dari gambar 7 dapat diketahui bahwa variabel salinitas dengan nilai 1,2\% memiliki laju korosi 571,911 MPY, nilai salinitas 1,0\% memiliki laju korosi 263 MPY dan nilai salinitas 0,7\% memiliki laju korosi 230 MPY. Dari data yang sudah diketahui dapat disimpulkan bahwa semakin besar nilai salinitas semakin tinggi laju korosinya (Benea et al., 2020).

\section{SIMPULAN}

Penelitian yang penulis lakukan dapat disimpulkan bahwa, berdasarkan pengujian salinitas dapat diketahui bahwa variabel air laut yang tidak diganti memiliki nilai salinitas yang 
paling tinggi sebesar rata rata $1,2 \%$, hal ini disebabkan air laut yang tidak diganti cenderung volume air menurun karena menguap dan kandungan garam mengendap.

Pengujian laju korosi yang dilakukan dapat diketahui bahwa variabel air laut yang tidak diganti memiliki laju korosi yang paling tinggi dengan nilai 571, 911 MPY.

Hubungan kandungan salinitas dan laju korosi dari data yang didapat dari pengujian diketahui bahwa variabel air laut tidak diganti dengan nilai salinitas 1,2 \% memiliki nilai laju korosi 571,911 MPY sehingga dapat disimpulkan semakin tinggi salinitas semakin cepat laju korosi yang terjadi.

\section{DAFTAR PUSTAKA}

Abbas, M., \& Shafiee, M. (2020). An overview of maintenance management strategies for corroded steel structures in extreme marine environments. Marine Structures, 71 , 102718. https://doi.org/https://doi.org/10.10 16/j.marstruc. 2020.102718

ASTM International. (2015). ASTM D2688 - 15e1: Standard Test Method for Corrosivity of Water in the Absence of Heat Transfer (Weight Loss Method). ASTM International.

https://doi.org/10.1520/D268815E01

Benea, L., Simionescu, N., \& Mardare, L. (2020). The effect of polymeric protective layers and the immersion time on the corrosion behavior of naval steel in natural seawater. Journal of Materials Research and Technology, 9(6), 13174-13184. https://doi.org/https://doi.org/10.10 16/j.jmrt.2020.09.059

Bialystocki, N., \& Konovessis, D. (2016). On the estimation of ship's fuel consumption and speed curve: A statistical approach. Journal of Ocean Engineering and Science, 1(2),

157-166. https://doi.org/https://doi.org/10.10 16/j.joes.2016.02.001

Gong, C., Frangopol, D. M., \& Cheng, M. (2020). Risk-based decisionmaking on corrosion delay for ship hull tankers. Engineering Structures, 212. https://doi.org/10.1016/j.engstruct. 2020.110455

Hu, Y., Wu, S., Withers, P. J., Cao, H., Chen, P., Zhang, Y., Shen, Z., Vojtek, T., \& Hutař, P. (2021). Corrosion fatigue lifetime assessment of high-speed railway axle EA4T steel with artificial scratch. Engineering Fracture Mechanics, 245, 107588. https://doi.org/https://doi.org/10.10 16/j.engfracmech.2021.107588

Kim, D. K., Wong, E. W. C., \& Cho, N.K. (2020). An advanced technique to predict time-dependent corrosion damage of onshore, offshore, nearshore and ship structures: Part $\mathrm{I}=$ generalisation. International Journal of Naval Architecture and Ocean Engineering, 12, 657-666. https://doi.org/https://doi.org/10.10 16/j.ijnaoe.2020.06.007

Komite Nasional Keselamatan Transportasi RI. (2016). Data Investigasi kecelakaan pelayaran tahun 2010-2016.

Li, H., Yu, H., Zhou, T., Yin, B., Yin, S., \& Zhang, Y. (2015). Effect of tin on the corrosion behavior of sea-water corrosion-resisting steel. Materials \& Design, 84, 1-9. https://doi.org/https://doi.org/10.10 16/j.matdes.2015.06.121

Okumoto, Y., Takeda, Y., Mano, M., \& Okada, T. (2009). Design of Ship Hull Structures. In Hull Structure Design System (pp. 81-95). Springer.

https://doi.org/https://doi.org/10.10 07/978-3-540-88445-3_4

Pérez, F., \& Clemente, J. A. (2011). Constrained design of simple ship hulls with B-spline surfaces. Computer-Aided Design, 43(12), 1829-1840. 
https://doi.org/https://doi.org/10.10 16/j.cad.2011.07.008

Refait, P., Grolleau, A.-M., Jeannin, M., François, E., \& Sabot, R. (2018). Corrosion of mild steel at the seawater/sediments interface: Mechanisms and kinetics. Corrosion Science, 130, 76-84. https://doi.org/https://doi.org/10.10 16/j.corsci.2017.10.016

Sasono, E. J. (2010). Efektifitas penggunaan anoda korban paduan aluminium pada plat baja kapal
AISI 2512 terhadap laju korosi di dalam media air laut. Universitas Diponogoro.

Zayed, A., Garbatov, Y., \& Guedes Soares, C. (2018). Corrosion degradation of ship hull steel plates accounting for local environmental conditions. Ocean Engineering, 163, 299-306. https://doi.org/https://doi.org/10.10 16/j.oceaneng.2018.05.047 